\title{
O papel da leitura em línguas estrangeiras na pós-graduação em Linguística segundo professores, disciplinas e pesquisas de mestrado e doutorado
}

The role of reading in foreign languages in the post-graduation in Linguistics according to professors, courses, and master and doctoral researches

Dohane Julliana, ROBERTO (UFSC/PMF) ${ }^{1}$

Ana Cláudia de, SOUZA (UFSC) ${ }^{2}$

\section{RESUMO}

A leitura é um dos principais meios de estudo e aprendizagem em todos os níveis de escolarização; todavia, se na educação básica destina-se atenção ao desenvolvimento dessa competência, a partir do ensino superior pressupõe-se que os/as estudantes já tenham se tornado experientes e proficientes, sendo a leitura seu principal meio de acesso ao conhecimento científico. Trataremos, neste estudo, da leitura na pós-graduação, espaço em que, além de se pressupor condição leitora para os estudos, exige-se a capacidade de ler em língua estrangeira (LE). Especificamente, discutiremos o papel da leitura em LE em um programa de pós-graduação em Linguística, por meio de entrevistas com professores/as e do levantamento das referências em dissertações e teses e nos planos de ensino das disciplinas. Os resultados indicam que a leitura em LE exerce papel fundamental para estudo e realização de pesquisas. No entanto, ainda há percalços que se impõem a um uso mais efetivo de textos em línguas estrangeiras, como o despreparo discente e a falta de clareza sobre o nível de proficiência necessário às atividades acadêmicas neste nível de estudo e aperfeiçoamento.

Palavras-Chave: Leitura, Leitura em línguas estrangeiras, Leitura na pós-graduação, Proficiência em leitura em língua estrangeira.

\section{ABSTRACT}

Reading is one of the main approaches to study and learning in all educational level, however, if during elementary school much attention is given to the development of this competence, in the graduation level it is inferred that students have already become expert and proficient in it, as reading is the main method to access scientific knowledge. In this study, we will approach the reading in the postgraduate education, which besides demanding reading skills, also requires the capacity to read in foreign languages (FL). Specifically, we intend to discuss the role of foreign language reading in a postgraduate program in the Linguistic area, by interviewing professors and checking the references in FL used in their lesson plans, as well as checking references used in dissertation and thesis. Our results indicate that FL reading is essential to study and research. Nevertheless, there are still mishaps in order to have a more effective use

\footnotetext{
${ }^{1}$ Universidade Federal de Santa Catarina, Florianópolis, Santa Catarina, Brasil. Prefeitura Municipal de Florianópolis; ORCID: https://orcid.org/0000-0001-6958-5041; dojuro@gmail.com

${ }^{2}$ Universidade Federal de Santa Catarina, Florianópolis, Santa Catarina, Brasil. Departamento de Metodologia de Ensino e Programa de Pós-Graduação em Linguística; ORCID: https://orcid.org/0000-0002-0833-6903; ana.claudia.souza@ufsc.br
} 
of foreign language texts, such as the students' lack of linguistic preparation and the absence of a clear notion about the proficiency levels necessary for the academic activities in this educational level.

Keywords: Reading, Reading in foreign languages, Reading in post-graduation level, Reading proficiency in foreign languages.

\section{Introdução}

Há muitas pesquisas que tratam do papel da leitura no contexto educacional brasileiro, considerando-a uma das competências mais eficientes quando se trata de estudo (SOUZA, 2003; SOSSAI, 2009; TAZAWA, 2009; DINIZ, 2012). No entanto, ainda pouco se fala de seu papel quando o assunto é o ensino superior ou a pós-graduação, por considerar que o estudante dessa etapa de escolarização já tem experiência e domínio proficiente da leitura e da escrita, sendo elas elementos imprescindíveis ao desenvolvimento das pesquisas, o que inclui acesso a textos não apenas em língua portuguesa - L1 para a maioria dos/as estudantes -, mas também em LE, principalmente, inglês.

Considerando esse cenário, este artigo traz recorte e reflexão acerca da pesquisa de mestrado de Roberto (2019), que foi desenvolvida com o objetivo de investigar o papel exercido pela leitura em LE, inglês, em um programa de pós-graduação em Linguística de uma universidade pública federal. O referido estudo surgiu da constatação das autoras de que, mesmo sendo aprovados/as em testes de proficiência em LE de sua instituição universitária, os/as pós-graduandos/as apresentavam dificuldades em leitura dos textos na língua em que haviam sido considerados/as proficientes. Isso posto, procurou-se investigar o grau de relevância da literatura em LE naquele contexto, bem como a adequação (níveis de leitura exigido) dos testes institucionais para avaliar a condição leitora de mestrandos/as e doutorandos/as da área.

O recorte selecionado para este artigo trata das expectativas e exigências de docentes do Programa de pós-graduação, por meio de entrevistas de cunho narrativo e de organização semiestruturada (FLICK, 2009; GRAY, 2012), e apresenta também análise das referências dos planejamentos de disciplinas, bem como das utilizadas em trabalhos de conclusão: teses e dissertações. Por meio das entrevistas e da análise documental, nosso objetivo foi reconhecer e descrever as perspectivas dos/as docentes em relação à leitura em LE e investigar a ocorrência de referências em LE nos referidos documentos, de modo a propor uma explicação ao fenômeno investigado.

Este estudo se mostra relevante, pois há pouca informação sobre o quanto o/a candidato/a deve se preparar, em termos de leitura, seja em sua língua materna ou em línguas estrangeiras, para cursar a pósgraduação stricto sensu e quão útil e necessária essa habilidade será na sua formação acadêmica e no desenvolvimento de seu estudo e pesquisa. Ademais, à pós-graduação é relevante conhecer e discutir aspectos de avaliação dos/as seus/suas candidatos/as e estudantes, a fim de criar condições para o 
enfrentamento das características que constituem a formação de pesquisadores/as e o fazer pesquisa neste nível acadêmico.

\section{Razão histórica da exigência de proficiência em línguas estrangeiras para os cursos de pós- graduação stricto sensu e seu reflexo na atualidade}

Antes de partirmos para o cerne do que será apresentado neste artigo, optamos por descrever as relações entre pós-graduação stricto sensu e proficiência em línguas estrangeiras, dada a sua relevância ao contexto da discussão que aqui propomos. Atualmente, a maioria das universidades que oferecem cursos de pós-graduação stricto sensu prevê, no regimento de seus programas, que o/a estudante deve comprovar proficiência em língua estrangeiras como requisito obrigatório. No entanto, muitas vezes, não está claro para os/as discentes o porquê dessa exigência. Algumas pesquisas, como a de Zanella (2003), apontam que mesmo coordenadores/as de cursos podem não ter clareza sobre esse requisito.

Na realidade, essa exigência está relacionada à constituição dos cursos de pós-graduação no Brasil, elaborada por Newton Sucupira no Parecer 977 de 1965. Nesse documento, cujo intento era definir e regulamentar os cursos de pós-graduação no Brasil, mestrandos/as e doutorandos/as deveriam ter formação científica sólida, sendo para tal conhecedores/as de línguas estrangeiras. Os cursos que se intentava implantar por aqui seguiam os modelos das universidades europeias e norte americanas e não se destinavam à formação de educação de massa, tratando-se de "treinamento intensivo com objetivo de proporcionar sólida formação científica" (SUCUPIRA, 1965, p. 7).

Percebe-se, na afirmação de Sucupira, que a pós-graduação no Brasil foi pensada para atender a apenas um estrato da população, uma elite com melhores condições de acesso à educação especializada e a línguas estrangeiras. Esse panorama, no entanto, não é o mesmo nos dias atuais, em que se conquistou democraticamente acesso mais amplo a esse nível de formação acadêmica, o que fez com que o perfil discente em relação à LE passasse por mudança considerável, uma vez que parte dos/as pleiteantes a vagas nos programas provém de educação básica e superior que não oferece condições suficientes à aprendizagem de uma LE e de contextos socioeconômicos não favoráveis à promoção do acesso a outras línguas.

Mesmo com mudanças do perfil discente da pós-graduação no Brasil, pesquisas têm apontado a condição de ler em LE como um fator sine qua non para o desenvolvimento de estudos científicos. Para Siqueira (2009, p.17, ajuste textual nosso), "a comunidade acadêmica pressupõe que o conhecimento prévio de uma língua estrangeira habilitaria [o] candidato a se tornar um sujeito mais autônomo no que diz respeito à realização de sua pesquisa e ao material estrangeiro ao qual ele passaria, então, a ter acesso". Já Divardin (2012) salienta que, além de favorecer o acesso às publicações científicas, a língua estrangeira 
também viabiliza a publicação internacional das pesquisas brasileiras. Em outras palavras, mesmo diante de um possível despreparo dos/as atuais candidatos/as, a importância da leitura em LE segue relevante.

Nesse cenário, no entanto, não é homogêneo o modo como os programas de pós-graduação (PPG) se posicionam em relação à comprovação de proficiência. Há programas de Letras ou Linguística que exigem a proficiência logo no processo seletivo, como é o caso da Universidade de Campinas (UNICAMP), de São Paulo (USP) e de Brasília (UNB) e as federais de Minas Gerais (UFMG) e do Rio Grande do Sul (UFRGS). E há aqueles que exigem a comprovação durante o estudo, em seu primeiro ano de formação, a exemplo da Federal de Santa Catarina (UFSC), do Rio Grande do Norte (UFRN) e da Estadual de Maringá (UEM). ${ }^{3}$

O PPG selecionado para este estudo exige, em seu Regimento de 2018, que o/a estudante comprove proficiência em uma língua estrangeira no primeiro ano de mestrado e em duas línguas estrangeiras, sendo obrigatório o inglês, no segundo ano do doutorado. Nesse tipo de situação circunscrita, o/a estudante não tem qualquer informação prévia do grau de conhecimento do idioma estrangeiro que terá de demonstrar ou que será exigido em sua formação acadêmica.

Essa situação pode provocar percalços, a exemplo de os/as discentes não conseguirem acessar os textos em LE propostos nas disciplinas do Programa, bem como textos fundantes para o desenvolvimento de suas pesquisas de tese ou dissertação. Assim, os dados obtidos por meio das entrevistas com os/as professores do PPGL, da análise das referências dos Planos de Ensino e dos trabalhos de conclusão são relevantes para esclarecer o papel que a leitura em LE tem exercido no contexto do PPGL nos últimos anos, considerando sua importância e exigência. Essa informação pode ser de grande valia não só para os/as candidatos/as aos cursos de mestrado e doutorado do Programa, mas também para o público em geral, interessado em cursar pós-graduação stricto sensu, assim como para os próprios programas de pósgraduação, para além do contexto particular investigado.

\section{A leitura nesta pesquisa: conceitos-chave para o desenvolvimento do estudo}

Embasamo-nos em abordagem teórica que assume a leitura como uma competência que abrange um conjunto de habilidades relativas à compreensão do texto escrito segundo determinados objetivos e em contexto e situação específicos. A compreensão envolve diferentes processos e níveis, desde o reconhecimento lexical até a compreensão inferencial e a representação mental do texto (KINTSCH;

\footnotetext{
${ }^{3}$ Informações obtidas por meio do edital de seleção para o ano de 2020 da UEM e do Regimento do curso de mestrado em Letras da UFRN. Disponível em: https://sigaa.ufrn.br/sigaa/public/programa/portal.jsf?lc=pt_BR\&id=7762. Acesso em $10 \mathrm{de}$ janeiro de 2018.
} 
RAWSON, 2013; SOUZA; SEIMETZ-RODRIGUES; WEIRICH, 2019). Conforme Souza, SeimetzRodrigues e Weirich (2019, p. 166),

[d]izer que a leitura é uma competência implica [...] considerá-la como um conjunto de habilidades não compulsórias e não espontâneas (ou pelo menos, não espontâneas enquanto não forem aprendidas) que precisam ser elaboradas, desenvolvidas e praticadas, a fim de que se saiba o que fazer e como fazer quando se lê, para que o propósito de alguma sorte de produção de sentidos [...] tenha chance de ser obtido, ou seja, de que haja possibilidade de desencadeamento de um processo de representação mental e retextualização do escrito.

Autores como Gagné, Yekovich e Yekovich (1993), por sua vez, propõem que a compreensão em leitura implica processos que permitem aceder o conteúdo literal e processos que demandam inferenciação. Os primeiros referem-se à compreensão da base do texto, enquanto os segundos estão relacionados ao modelo situacional, devido à maior necessidade de o/a leitor elaborar, integrar e realizar inferências.

Pesquisas indicam que esses mesmos processos ocorrem quando da leitura em uma língua estrangeira. No entanto, caso o nível linguístico na LE não seja suficiente, o processamento em leitura é impactado, impedindo que os níveis superiores sejam alcançados. Em outras palavras, um bom leitor em língua materna (LM) só mantem sua habilidade em leitura em LE se possuir suficiente proficiência linguística.

\section{Método}

Considerando seus objetivos, esta pesquisa se caracteriza por ser descritiva e explicativa (GIL, 2010), já que tem o intuito de identificar, compreender e explicar o papel da leitura em LE na pósgraduação stricto sensu, considerando as expectativas dos/as docentes e o uso efetivo de referências em LE em trabalhos científicos e Planos de Ensino de programa de pós-graduação em Linguística. Quanto ao método, visando à triangulação de informações a fim de mais adequadamente compreender o contexto e o tema investigados (FLICK, 2009), propõe-se pesquisa qualitativa e quantitativa, dada à natureza dos dados obtidos por meio de entrevistas e de análises documentais.

Os/As participantes aderiram voluntariamente à pesquisa, sendo sete professores/as permanentes do Programa, que ofertam regularmente disciplinas e orientam teses e dissertações. A aprovação ética do estudo ocorreu em 29 de abril de 2018, pelo Comitê de Ética em Pesquisas com Seres Humanos, sob o Parecer $n^{0} 2.627 .685$.

Os/As professores/as foram convidados/as a participar de entrevistas, que seguiram o modelo narrativo e semiestruturado (FLICK, 2009; GRAY, 2012), articuladas em torno de questões que 
abordaram aspectos de leitura concebidos e adotados pelos/as professores/as com vistas à formação dos/as pós-graduandos/as. Descrevemos as vozes dos/as docentes entrevistados/as por meio de códigos, tais como: PPGL01, PPGL02 e assim sucessivamente.

As manifestações dos/as docentes foram incitadas por quatro grupos de questões-guia: 1) Como você concebe a leitura na pós, especialmente em língua estrangeira? Qual o papel dela na formação do/a pós-graduando/a na Linguística?; 2) Qual nível de leitura você considera satisfatório para o estudo dos textos das disciplinas que você ministra e para a fundamentação das pesquisas de pós-graduação? O que os/as discentes devem desempenhar diante de um texto, seja em língua portuguesa, seja em língua estrangeira, para que você considere que ele/a teve um bom desempenho?; 3) Em que medida a leitura em LE é requerida nos trabalhos de conclusão dos/as seus/suas orientandos/as?; e 4) Há utilização de textos traduzidos em suas disciplinas? Se sim, existe alguma preferência pelo texto traduzido?.

Tais perguntas foram elaboradas considerando que a formação do/a estudante leitor/a (em LM ou LE) não deve ser menosprezada na pós-graduação sob o pressuposto de que, por estar em uma pósgraduação stricto sensu, ele/a já é proficiente em leitura na sua LM e já tem preparação suficiente em LE. Para isso, conhecer a concepção de leitura dos/as docentes e os níveis e habilidades necessários para estudo e pesquisa é fundamental para entender não só o papel da leitura, mas também a relação entre ensino e aprendizagem em tal contexto.

Em relação à análise das referências utilizadas nos Planos de Ensino, foram analisados os Planos das disciplinas obrigatórias do Programa, as quais são divididas em disciplinas do grupo 1 (Linguística Geral, Semântica, Sintaxe, Fonologia e Morfologia) e disciplinas do grupo 2 (Linguística Aplicada, Psicolinguística, Sociolinguística e Dialetologia). A escolha dessas disciplinas se justifica pela sua regularidade de oferta e obrigatoriedade, sendo que o/a estudante de mestrado ou doutorado deve cursar duas disciplinas do grupo 1 e uma disciplina do grupo 2 para integralização dos créditos. Assim, como os/as mesmos/as docentes são responsáveis por ministrar determinadas disciplinas, analisamos o último Plano de Ensino dentro do período de análise (2015 a 2018), pois sendo o/a mesmo/a docente que ministra determinada disciplina, não seria de se esperar que houvesse mudança significativa em seu Plano de Ensino, em tão curto intervalo de tempo.

Quanto aos trabalhos de conclusão de curso (dissertações e teses), foram analisados 72 documentos disponibilizados no repositório da Biblioteca Universitária da UFSC (BU), defendidos entre os anos de 2015 e 2017. Como parte da pesquisa foi conduzida no ano de 2018 e parte em 2019 e como pode ocorrer relativa demora para as teses e dissertações defendidas chegarem à biblioteca para, só a partir de então, serem disponibilizadas, optamos por não incluir o ano de 2018 nas buscas. 
A análise teve orientação quantitativa, ou seja, analisamos o total de referências em LE de modo geral e também a quantidade de referências em cada LE encontrada nos trabalhos defendidos: inglês, espanhol, francês, alemão e italiano. Ressaltamos o fato de que não consideramos obras traduzidas, uma vez que nosso objetivo foi analisar a leitura em língua estrangeira em si. Além disso, o acesso a tais obras não seria viável por meio da análise dos registros das referências, pois, equivocadamente, nem sempre os autores das dissertações e teses indicam que se trata de obra traduzida.

\section{Leitura em LE: como os/as docentes a concebem e o que esperam?}

Indagados/as sobre suas concepções de leitura e o papel dela na formação do/a pós-graduando/a, a maioria dos/as docentes se pronunciou dizendo que a leitura em LE tem muita relevância para a formação do/a pós-graduando/a, a exemplo da fala de PPGL06: "Não uso a LE porque é uma exigência da pós-graduação, mas sim porque a leitura em LE é necessária”. Já outros/as professores/as salientam que, dentro de determinadas áreas da Linguística, os textos fundamentais são em LE, principalmente em inglês, pelo que diz PPGL02: "É raro encontrar textos relevantes que não sejam em língua inglesa", e PPGL06: “Eu não economizo o pós-graduando da bibliografia que é necessária”. Por outro lado, em outras áreas da Linguística, os/as professores/as afirmam que a literatura nacional já se desenvolveu o suficiente e não há tanta necessidade de consulta aos materiais estrangeiros, o que é assumido por PPGL03: "Temos bons textos produzidos nacionalmente".

Na maior parte das falas citadas, é evidente o papel da leitura em LE com fins de estudo, pois há a necessidade de ler para acessar e sedimentar conceitos-chaves de determinadas perspectivas teóricas. Outro ponto relevante é que, no cenário da pós-graduação, a leitura vai além da compreensão de textos: o/a discente é requisitado/a a refletir, contextualizar e elaborar sobre o conteúdo lido. Desse modo, essas demandas podem requerer dos/as discentes elevados níveis de leitura, tanto em LM quanto em LE.

Quanto à questão que visa conhecer o nível de leitura que o/a professor/a considera satisfatório para o estudo dos textos, tanto com vistas ao acompanhamento das aulas quanto ao desenvolvimento dos trabalhos de conclusão, observamos que uma leitura aprofundada e elaborativa seria requerida dos/as discentes para atender às demandas, ou seja, acessar teorias e conceitos-chave relativos à sua pesquisa. No entanto, quando indagados/as diretamente sobre o nível considerado adequado para realização de tais tarefas, houve variações nas falas dos/as docentes. Tanto o nível intermediário quanto o avançado foram indicados como satisfatórios, mas sem que o/a professor/a explicasse o porquê de ter indicado tal nível, tampouco o que ele significa e implica. Em outras palavras, não há clareza em relação ao desempenho esperado de um/a estudante considerado/a nos níveis de proficiência citados, o que vai ao encontro das 
constatações de Siqueira (2009) sobre a falta de clareza em relação ao conceito de proficiência no contexto da pós-graduação no Brasil.

Outro fator em relação ao nível de proficiência é a construção de metalinguagem dentro das áreas específicas da Linguística. Segundo os/as docentes, quando o/a discente constrói uma boa metalinguagem em sua área de estudo, esse conhecimento mitiga a necessidade de se ter um nível de leitura em LE tão alto. Podemos encontrar essa assunção na voz de PPGL02: “Geralmente o aluno desenvolve a habilidade de fazer uma leitura técnica $[. .] "$, "Conhecendo o vocabulário técnico da área te permite fazer uma boa leitura, mesmo não tendo uma proficiência tão alta”. Entretanto, esta não é a visão de todos/as os/as professores/as entrevistados/as. Para PPGL07, por exemplo, o conhecimento de vocabulário técnico não dispensa uma boa proficiência na língua-alvo, mesmo que seja grande aliado contra a barreira linguística imposta pelos textos acadêmicos. Assim, para PPGL07: “O não domínio do vocabulário técnico (assunto) traz problemas de compreensão até em língua materna", o que é coerente com o que diz PPGL04: "As disciplinas formais trazem conteúdos complexos que por si só criam condições de incompreensão, aliando-se à barreira linguística".

A respeito do vocabulário, é importante discutir seu papel na leitura em LM e em LE. Tomaremos como referência as considerações de Leffa (1996) sobre construção de schemata e de autores que discutem a leitura no processo de transferência de código linguístico (CLARKE, 1979; BERNHARDT; KAMIL, 1995), como é o caso da leitura em LE. Em Leffa (1996), encontramos a assunção de que o schemata é um conceito associado ao conhecimento prévio que acumulamos durante a vida no qual está inserido nosso conhecimento vocabular e nossa metalinguagem. Assim, se o schemata é importante para a leitura em LM, também o será para a leitura em LE, pois segundo as evidências da Teoria do Limiar Linguístico (CLARKE, 1979; BERNHARDT; KAMIL, 1995), um nível adequado de conhecimento linguístico na LE é necessário para que o sujeito possa fazer uso efetivo de habilidades da língua como a leitura. Nesse sentido, nosso schemata pode aliviar o processamento no nível microestrutural, quando aliado ao conhecimento da sintaxe e de elementos coesivos responsáveis pela costura das ideias textuais. Contudo, pode não garantir o acesso aos níveis superiores de leitura, se o sujeito não tem proficiência linguística na LE e suficiente competência leitora.

Em relação ao nível de proficiência (intermediário a fluente) indicado pelos/as docentes, ressaltamos que não há parâmetros sobre o nível de proficiência linguística adequado para que o sujeito possa fazer uso eficiente de sua habilidade de leitura em LE. No entanto, de acordo com a grade de referência do ACTFL (2012), um/a usuário/a de nível intermediário é capaz de compreender textos simples, de baixa complexidade estrutural e como vocabulário de alta frequência, o que não parece compatível com que os/as professores/as dizem ser as demandas de leitura da pós. Há aqui, novamente, 
uma indicação de incerteza da associação entre demanda e nível de proficiência, ou seja, os/as professores/as conhecem as demandas do Programa, mas se sentem inseguros/as quando indagados/as sobre o que é necessário para atender tais demandas.

Diante disso, o nível fluente de leitura seria aquele mais adequado às demandas da pós-graduação, considerado na descrição da referência do ACTFL (2012) como nível superior. Segundo essa descrição, no nível superior, o sujeito é capaz de ler textos de diversas esferas (incluindo a acadêmica), também é capaz de alcançar níveis de compreensão mais profundos de informações implícitas e compreender variados tipos de argumentos propostos no texto. O/a docente PPGL05 parece concordar com essa assunção, quando enfatiza que: "Eu acho que tem que ser leitura fluente".

Sobre o desempenho esperado de um/a estudante diante de um texto em atividades de leitura na pós-graduação, as respostas não revelaram grandes detalhes sobre as expectativas dos/as docentes. Não houve menção a abordagens do texto a depender dos objetivos, como, por exemplo, ler para compreender diferentes perspectivas teóricas, ler para apreender aspectos teóricos e conceituais relevantes, ler para debater determinado ponto de vista teórico, ler para apresentar um seminário, ler para escrever um artigo ou a dissertação ou tese, entre outros. Pode-se tomar como resumo das falas o que foi dito por PPGL02: "A leitura em LE é fundamental para acessar os textos da área".

Convém ressaltar que seria de muita valia ao/à pós-graduando/a ser informado/a e orientado/a sobre as exigências em relação à leitura (em LM e LE) que ele/a terá de atender enquanto cursa mestrado ou doutorado, pois, nesse contexto, é essa habilidade que irá permear e até delinear toda sua trajetória acadêmica. Em outras palavras, mestres/as e doutores/as são formados/as com base em leitura e produção de textos, e não é incomum que a alta demanda desses dois processos cause estranhamento ao/à discente ingressante e, em muitos casos, leve-os/as a ter baixo rendimento acadêmico, afetando inclusive sua condição afetiva e psíquica, como se pode observar nas respostas ao questionário sobre saúde mental, realizado pelo Programa de pós-graduação em Linguística, no qual os/as discentes relatam angústias em relação ao cumprimento de prazos, à instabilidade da educação superior, à quantidade de leituras obrigatórias, entre outros ${ }^{4}$.

Quanto à exigência de leitura em LE nos trabalhos de conclusão de seus/suas orientandos/as, as respostas revelaram que os textos de orientação de teses e dissertações são indicados de acordo com sua relevância à área de estudo da Linguística. Assim, o grau de utilização de textos em LE depende de quanto essa área está relacionada a publicações internacionais. Nesse sentido, alguns/as docentes - a exemplo de

\footnotetext{
${ }^{4} \mathrm{O}$ documento contendo a enquete sobre saúde mental dos/as estudantes foi acessado por meio do link: https://poslinguistica.paginas.ufsc.br/files/2019/04/question\%C3\%A1rio-de-sa\%C3\%BAde-mental.pdf. Acesso em: 13 de dezembro de 2019.
} 
PPGL01, PPGL03 e PPGL07 - afirmam já ser possível embasar pesquisas em determinadas áreas da Linguística por meio da produção científica nacional, mesmo que os textos estrangeiros sejam ainda bastante relevantes. Inclusive, um/a dos/as docentes se posiciona a favor da valorização da ciência brasileira, sendo contrário/a à importação de teorias: "Do Brasil para o mundo" (PPGL01).

Outros/as docentes, no entanto, dizem não haver outros meios de fundamentar pesquisas a não ser pelo acesso constante a textos em LE. Esses/as docentes relatam que, desde a graduação, estudantes interessados/as em cursar áreas da Linguística como a Sintaxe e a Semântica, por exemplo, preparam-se linguisticamente para tal, por saberem da necessidade de leitura em LE para entender conceitos fundantes. Dentro dessa premissa, os/as professores esperam que seus/suas futuros/as orientandos/as já venham preparados/as para a pós-graduação, o que é ilustrado nas falas de PPGL05: "Sem inglês, impossível. É uma questão que nem se coloca", de PPGL06: "Nem pergunto. Eles têm que se virar", "É o mínimo que eu espero de um pós-graduando" e de PPGL07: "Não tem desculpa. Tem que ler”. Essas afirmações são indicativas de que, para esses/as professores/as, a leitura em LE não é um simples requisito burocrático nem uma questão de escolha, mas uma necessidade intrínseca ao contexto da pós-graduação. Desse modo, seu uso efetivo se deve ao grau de necessidade de se amparar em textos internacionais para fundamentar as pesquisas produzidas no Programa.

A última questão se referia à posição dos/as professores/as em relação ao uso de traduções de textos científicos nas disciplinas ministradas e na orientação de trabalhos de conclusão: dissertação e tese. $\mathrm{Na}$ verbalização de alguns/mas docentes, é evidente a resistência em relação à leitura em LE por parte dos/as pós-graduandos/as. Além da resistência, os/as docentes ressaltam que, devido ao contato mais distante com os/as discentes que não são seus/suas orientandos/as, é difícil supervisionar a leitura dos textos disponibilizados nas disciplinas ministradas no Programa: se realmente eles/as leem, o quanto leem e em quais condições leem.

Dessa maneira, os/as docentes temem não estar sendo informados/as sobre possíveis problemas que os/as discentes encontram quando leem textos em línguas estrangeiras, ou seja, há a possibilidade de a incipiência dos/as pós-graduandos/as não estar sendo relatada tampouco percebida. Nesse sentido, quando reclamações sobre tais leituras ocorrem, os/as professores/as tentam mitigar a dificuldade dos/as estudantes diminuindo a quantidade de textos em LE nas referências dos Planos de Ensino das disciplinas que ministram, como se observa no dizer de PPGL04: “Tento fazer um uso menor de textos em LE", e de PPGL05: "Eu mesclo". Já outros/as docentes optam pelo uso de textos traduzidos, mesmo não concordando com tal atitude, como diz PPGL04: "Não confio nas traduções, mas trabalhamos com o que temos". Outro ponto relevante em relação ao uso de traduções se refere ao uso de ferramentas eletrônicas como o Google tradutor sobre o qual os/as docentes relatam não terem conhecimento acerca de seu uso 
(ou não) por parte dos/as estudantes, tampouco terem condições de avaliar quão eficazes e eficientes essas ferramentas podem ser na leitura de textos científicos.

Concluímos a análise dos dados obtidos por meio das entrevistas, resgatando o que os/as docentes do PPGL verbalizaram sobre a leitura, em LM e em LE, para o contexto pesquisado. Nesse cenário, os/as professores/as apontam tanto a importância fundamental da leitura quanto o despreparo discente diante dessa competência. Mesmo não sendo pauta das entrevistas, a falta de engajamento dos/as pósgraduandos/as com a leitura foi um ponto importante a ser considerado, pois sem o devido preparo, elas/as podem não atender aos requisitos exigidos pelo Programa resultando em baixo desempenho. Além disso, frente a esse despreparo, os/as professores/as tendem a diminuir ou substituir obras importantes de seus Planos de Ensino, a fim de prevenir o insucesso. Segundo PPGL07: "No ensino superior é difícil criar o hábito de o aluno se preparar para estar nas aulas por meio da leitura". "A leitura é muito negligenciada pelos/as estudantes" e "É a base de tudo e o calcanhar de Aquiles de tudo". Em síntese, se os/as professores/as não priorizam a leitura em LM, também não o farão quanto à leitura em LE.

Diante do exposto, resgatamos os postulados de Newton Sucupira sobre a formação do/a pósgraduando/a e da necessidade de ele/a ser um/a conhecedor/a de línguas estrangeiras e concluímos que essa necessidade é real, a fim de que se tenha acesso a pesquisas realizadas para além do âmbito nacional, de sorte a buscar mais ampla consistência teórica e metodológica não apenas à formação do/a pesquisador/a como estudioso/a e leitor/a, mas também como aquele/a que produz pesquisa e que deseja que ela seja lida para além de seu espaço mais íntimo de circulação. No entanto, os/as pós-graduandos/as têm de ter informações claras e consistentes sobre as exigências dos programas aos quais pretendem se candidatar para que possam atender de forma satisfatória às exigências dos cursos de mestrado ou doutorado, considerando o perfil e o objetivo do nível de formação acadêmica que ele/a pretende acessar. O acasalamento entre exigência e preparação pode assegurar melhores condições à experiência acadêmica e afetiva, aos resultados para a produção científica do país, assim como manter ou impulsionar a qualidade dos cursos de pós-graduação.

\section{Análise do uso de textos em LE no contexto pesquisado}

Por meio das entrevistas com os/as docentes, pudemos entender que a leitura em LE é essencial para o estudo e o embasamento de pesquisas de pós-graduação, mas ou o despreparo ou a resistência discente fazem com que os/as docentes busquem adaptar suas abordagens, ora diminuindo a quantidade de obras disponibilizadas em LE, ora utilizando traduções. 
Nesta seção, iremos analisar o uso ou menção ${ }^{5}$ de textos em LE por meio da análise das referências utilizadas nos Planos de Ensino e nas teses e dissertações defendidas entre os anos de 2015 e 2017. Como já informado, esses dados foram complementares ao alcance do objetivo de investigar o papel que a leitura em LE exerce no contexto da pós-graduação, fornecendo indicações de o quanto essa atividade tem suprido as demandas de pesquisa e estudo em duas situações: 1) quando há indicação docente de estudo para uma disciplina específica; 2) quando há seleção pelo/a próprio/a estudante ou pelo/a professor/a orientador/a para o trabalho de conclusão (tese ou dissertação).

O resultado dessa análise pode oferecer insumos para refletir sobre a relação entre as demandas em leitura na pós-graduação e a seleção de textos em LE nas disciplinas e na produção acadêmica discente. Nessa perspectiva, os resultados aqui apresentados poderão respaldar outras pesquisas que visem à investigação do papel da LE em outros programas de pós-graduação ou, até mesmo, em outros contextos universitários.

Iniciamos pela apresentação dos dados concernentes às referências encontradas nas teses e dissertações. Dos 72 trabalhos analisados, 16 foram defendidos em 2015, 24 em 2016 e 32 em 2017. Não foram encontradas referências em LE que não fossem nas seguintes línguas: inglês, espanhol, francês, alemão e italiano, línguas que, a propósito, constituem as línguas de formação dos cursos de graduação (licenciatura e bacharelado) em LE da mesma universidade a qual pertence o Programa de pós-graduação considerado. Ressalta-se, ainda, que essas são as línguas estrangeiras aceitas no regimento do Programa para comprovação de proficiência, indicando uma compatibilidade entre a exigência legal e o uso para produção acadêmica.

Os resultados demonstraram que, em 2015, as teses e dissertações apresentavam $30 \%$ de suas referências em LE. No ano de 2016 e 2017, essa porcentagem foi de $26,41 \%$ e $31,34 \%$, respectivamente. A LE mais utilizada é o inglês (média de uso: $25 \%$ nos três anos, considerando o montante total de referências), apresentando uma diferença robusta com o espanhol (média de uso: 2\% nos três anos, também considerando o montante total de referências), segunda LE mais utilizada. As demais LE foram utilizadas em menos de 1\% das referências, salvo a língua francesa cuja representatividade foi de 4,06\% em 2015. Esses dados respaldam o que foi afirmado pelos/as docentes de que a necessidade de uso de referência em LE está relacionada, em grande medida, à importância que algumas áreas da Linguística, como a Sintaxe, a Semântica, a Fonologia e a Psicolinguística, têm de se amparar em produções científicas estrangeiras, necessidade já superada, segundo entrevista de um/a dos/as docentes, por outras áreas, como

\footnotetext{
${ }^{5}$ Consideramos a menção, porque o fato de as obras serem citadas nos Planos e nos trabalhos de conclusão não necessariamente revela que tenham sido efetivamente lidas e estudadas.
} 
a Linguística Aplicada, por exemplo, cuja produção nacional é tida como suficiente para embasar a produção científica.

A média de 29,25\% de uso de referências em LE também pode, de certa maneira, indicar a condição leitora em LE dos/as pós-graduandos/as. Mesmo diante do relato de alguns/mas professores/as orientadores/as de que a leitura em LE é uma prática exigida dos/as orientandos/as, podemos inferir que, diante de um possível despreparo em relação a esse quesito, tanto orientadores/as quanto orientandos/as possam recorrer a alternativas, como substituição de textos, uso de obras traduzidas, ou emprego de ferramentas de tradução, estratégia indicada pelos/as professores/as durante as entrevistas, quando o texto em LE é mantido.

Assim, se houver substituição ou uso de obras traduzidas, o número de referências em LE é diminuído e, se houver uso exclusivo de ferramentas de tradução, a leitura em LE não ocorre. Com isso, não queremos dizer que é uma obrigação o/a pós-graduando/a ser leitor/a de uma LE determinada, já que o Regimento do Programa lhe dá a opção de escolher entre cinco línguas estrangeiras, tampouco desconsiderar a produção científica nacional em favorecimento às produções em LE. $\mathrm{O}$ que queremos apontar é a possibilidade de haver prejuízo à formação acadêmica de mestrandos/as e doutorandos/as quando há estreitamento no acesso a produções científicas para a condução de pesquisa.

Em continuação ao exame do uso de línguas estrangeiras na pós, apresentamos a análise quantitativa das referências em LE dos Plano de Ensino. Como já informado, analisamos somente disciplinas dos grupos 1 e 2, consideradas obrigatórias e com regularidade de oferta. As únicas línguas estrangeiras citadas nos Planos são o inglês, cuja menção aparece em quase todas as disciplinas, e o espanhol, que aparece em apenas algumas delas. Do total de referências, Fonologia, Semântica e Psicolinguística têm 33,33\% em LE, e Linguística Geral apresenta 20\%. Essas disciplinas apresentam referências apenas na LE inglês. As disciplinas que fazem uso de ambas as línguas são: Sintaxe (31,41\% inglês e 5,55\% espanhol) e Sociolinguística e Dialetologia (25\% inglês e 3,57\% espanhol). A Disciplina Linguística Aplicada não fez uso de referências em LE no período de oferta analisado: primeiro semestre de 2018, o que é coerente com a manifestação docente na entrevista.

Percebe-se, também nos Planos de Ensino, o uso mais frequente da língua inglesa como LE, sendo também observável que a porcentagem de utilização de referências em LE é similar àquela encontrada nos trabalhos de conclusão. Essa constatação corrobora o que é afirmado por Forattini (1997) de o inglês ser considerado, há décadas, a língua da ciência. Outro ponto significativo é o uso corrente de referências em LE em disciplinas como Fonologia, Semântica e Psicolinguística, o que é coerente com os dados obtidos na análise das referências das teses e dissertações defendidas no PPGL. Também, nos Planos de Ensino e nos trabalhos de conclusão de curso, não há disciplinas nem teses ou dissertações que utilizem 
apenas LE em suas referências. Outro fato observado é o de que, tanto nos trabalhos de conclusão, quanto no Plano de Ensino da Disciplina de Linguística Aplicada, o uso de referências em LE é restrito ou ausente. Essa evidência vai ao encontro das falas dos/as professores/as de que essa área da Linguística Aplicada já possui literatura nacional suficiente para embasar pesquisas, sendo o uso de referências em LE não tão necessário.

Com essa constatação, conclui-se que, na produção acadêmica de pós-graduandos/as, a opção de se orientar pela literatura nacional pode ser devida tanto à existência de produções abundantes em sua área de estudo, quanto ao nível de proficiência que o/a estudante tem para acessar textos em línguas estrangeiras. Por outro lado, em algumas áreas da Linguística, devido ao alto grau de influência das pesquisas publicadas em LE, não há como o/a estudante se esquivar do uso de referências em LE para produzir seu trabalho de conclusão de curso. Já na elaboração dos Planos de Ensino, o uso de referências em LE ou em língua materna pode ser determinado por fatores relacionados à relevância dos textos para tal área de investigação e à condição leitora do grupo de discentes matriculados/as.

Considerando esses aspectos, a avaliação da proficiência em LE não deve ser considerada apenas como um requisito burocrático, mas como uma ferramenta para medir o grau de preparação dos/as discentes para uma das necessidades mais vitais da pós-graduação: a leitura, assim como para, em alguma medida, tentar garantir o acesso e a produção de pesquisas que possam ser mais amplamente respaldadas e disseminadas, de sorte a também se tornarem referências para além do próprio espaço em que são produzidas.

\section{Considerações finais}

Pudemos apurar, nos dizeres dos/as professores/as, pelo menos dois fatores indicativos do uso ou não de referências em LE, sendo o primeiro o grau de relevância que os textos em LE têm para a área em que atuam e o segundo a preparação linguística em LE dos/as discentes do Programa.

As falas dos/as docentes que atuam na Fonologia, na Psicolinguística, na Sintaxe e na Semântica, por exemplo, indicam que a leitura de textos em LE é fundamental para o estudo e a pesquisa, o que confirma os dados quantitativos obtidos na análise dos Planos de Ensino dessas disciplinas: 33,33\%; $33,33 \%, 36,96 \%$ e 33,33\%, respectivamente, sendo essas as porcentagens mais altas em relação ao uso de referências em LE no contexto analisado. Por outro lado, a análise do Plano de Ensino disciplina de Linguística Aplicada revelou ausência de uso de referências em LE, o que foi explicado pelos/as professores/as atuantes por já existir literatura nacional, em língua portuguesa, suficiente para embasar as pesquisas. Não conseguimos entrevistar os/as professores/as de todas as áreas da Linguística, pois nem 
todos/as tinham disponibilidade no período em que as coletas foram realizadas. Dessa forma, não pudemos fazer a mesma análise com disciplinas como Sociolinguística e Linguística Geral.

O segundo fator que apuramos ser determinante para o uso de referências em LE, relacionado à preparação linguística em LE dos/as discentes, não foi explicitamente verbalizado por todos/as os/as docentes. Os/As professores/as que consideram a proficiência em LE como requisito para a pós-graduação dizem não receber reclamações quanto ao uso de referências em LE, bem como afirmam que não economizam no uso de textos em LE, quando necessário. Todavia, esses/as docentes relatam não ter condições de supervisionar se os/as pós-graduandos/as realmente cumprem com as obrigações em relação à leitura. Outros/as professores/as são mais explícitos/as sobre esse assunto e falam abertamente da falta de preparação de mestrandos/as e doutorandos/as em relação à leitura, principalmente em LE. Esse despreparo faz com que os/as professores/as, interessados/as em garantir o bom rendimento dos/as estudantes nas disciplinas, utilizem mais referências em língua portuguesa, o que inclui textos traduzidos, em seus Planos de Ensino. Além disso, a falta de clareza sobre o nível e o conceito de proficiência em leitura em LE, necessário ao estudo e à produção de pesquisa no contexto do PPGL, corrobora o despreparo discente, pois não oferece direcionamento do quanto eles/as têm de se preparar, também linguisticamente, para cursar a pós-graduação.

Desse modo, em resposta ao nosso primeiro questionamento, podemos afirmar que a leitura em LE exerce papel fundamental no contexto do PPGL, para o estudo e a condução de pesquisa, em maior ou menor grau dependendo da área da Linguística, mas a pouca condição de leitura em LE pode impactar o acesso a referências. Esse resultado é coerente com as assunções feitas por Siqueira (2009) e Divardin (2012) de que, no contexto acadêmico brasileiro, o conhecimento de uma LE, principalmente a língua inglesa, ainda é imprescindível tanto para se produzirem pesquisas, quanto para publicação internacional das produções científicas brasileiras.

Nesse sentido, se levarmos em consideração a necessidade do conhecimento de línguas estrangeiras para produzir e publicar no meio científico e a aparente falta de preparação discente em relação a esse aspecto, parecemos contemplar problemas relacionados aos critérios adotados por algumas instituições acadêmicas para selecionar candidatos aos cursos de mestrado e doutorado. Melhor dizendo, se ler em LE é necessário à pós-graduação, essa condição deveria estar explícita nos processos seletivos desses cursos. Desse modo, a não exigência da comprovação de proficiência em leitura em LE durante o processo seletivo, bem como a utilização de instrumentos avaliativos insuficientes para testar o nível de leitura de mestrandos/as e doutorandos/as, podem fazer com que os/as professores/as tenham que adaptar seus Planos de Ensino, de modo a atender a demanda da falta de preparo em relação à leitura em LE, 
resultando no ajuste da universidade à manutenção da realidade do/a estudante e não no impulsionamento de novas aprendizagens.

Para fechar este artigo, voltamos ao aspecto relativo às expectativa de que estudantes da pósgraduação stricto sensu tenham proficiência na leitura e na escrita, indicando que tal questão deva ser mais detidamente investigada, pois, como constatado nesta pesquisa, nesse nível de escolarização ainda há indícios de despreparo em relação a essas duas habilidades, mesmo se tratando de língua materna.

\section{Referências}

AMERICAN COUNCIL ON THE TEACHING OF FOREIGN LANGUAGES (ACTFL). Proficiency Guidelines, 2012. Disponível em: www.actfl.org. Acesso em: 09 de março de 2018.

ALDERSON, Charles. J. Reading in a foreign language: A reading problem or a language problem? In: ALDERSON, J. Charles; URQUHART, A. H. (eds.). Reading in a foreign language. London: Longman, 1984.

BERNHARDT, Elizabeth; KAMIL, Michael. Interpreting relationships between L1 and L2 reading: Consolidating the Linguistic Threshold and the Linguistic Interdependence Hypothesis. Applied Linguistics, n. 16, p.15-34, 1995.

CLARKE, Mark. Reading in Spanish and English: Evidence from ESL students. Language Learning, v. 29, n. 1, p. 121-150, 1979.

DIVARDIN, Gisele. W. Elaboração e validação de um modelo padrão de avaliação para exames de proficiência de leitura em inglês para ingressantes em Programas de Pós-Graduação na UTFPR Campus de Ponta Grossa. Orientador: Michael A. Watkins. 2012. Tese (Doutorado) - Programa de PósGraduação em Letras, Universidade Federal do Paraná. Curitiba, 2012.

DINIZ, Antônio G. The teaching and learning of reading at UERN Letras Course: the use of reading strategies concerning the development of EFL readers. Orientadora: Lêda Maria Braga Tomitch. 2012. Dissertação (Mestrado) - Programa de Pós-Graduação em Inglês. Universidade Federal de Santa Catarina. Florianópolis, 2012.

FLICK, Uwe. Introdução à pesquisa qualitativa. 3. ed. Trad. Joice Elias Costa. Porto Alegre: Artmed, 2009.

FORATTINI, Oswaldo Paulo. A língua franca da ciência. Rev. Saúde Pública, v.31, n. 1, p. 3-8, 1997. GAGNÉ, Ellen; YEKOVICH, Carol; YEKOVICH, Frank. The cognitive psychology of school learning. New York: Harper Collins College Publishers, 1993.

GIL, Antônio C. Como elaborar projetos de pesquisa. 5. ed. São Paulo: Atlas, 2010.

GRAY, David E. Pesquisa no mundo real. Trad. Roberto Cataldo Costa. Porto Alegre: Penso, 2012. KINSTSCH, Walter; RAWSON, Katherine. Compreensão. In: SNOWLING, Margareth; HULME, Charles. A Ciência da Leitura. Trad. Ronaldo Cataldo Costa. Porto Alegre: Penso, 2013.

LEFFA, Vilson. Aspectos da leitura: uma perspectiva psicolinguística. Porto Alegre: Sagra, 1996. ROBERTO, Dohane. J. Leitura em língua estrangeira: aspectos da demanda na pós-graduação e da avaliação em testes de proficiência. Orientadora: Ana Cláudia de Souza. 2019. Dissertação (Mestrado) Programa de Pós-Graduação em Linguística, Universidade Federal de Santa Catarina. Florianópolis, 2019.

SIQUEIRA, Ana Paula B. L. Representações de proficiência e a construção do inglês como língua necessária na pós-graduação. Orientadora: Deusa Maria de Souza Pinheiro Passos. 2009. Dissertação (Mestrado) - Faculdade de Filosofia, Letras e Ciências Humanas, Universidade de São Paulo, São Paulo, 2009. 
SOSSAI, Martha. A. Um estudo em estratégias de compreensão leitora num curso de letras. Orientadora: Maria Celina Teixeira Vieira. 2009. Dissertação (Mestrado) - Programa de Pós-Graduação em Educação: Psicologia da educação. Pontifícia Universidade Católica de São Paulo. São Paulo, 2009. SOUZA, Ana Cláudia de; SEIMETZ-RODRIGUES, Cristiane; WEIRICH, Helena Cristina. Ensinar a estudar ensinando a ler: potências dos roteiros de leitura. In: SOUZA, Ana Cláudia de; SEIMETZRODRIGUES, Cristiane; FINGER-KRATOCHVIL, Claudia; BARETTA, Luciane; BACK, Angela Cristina Di Palma (org.). Diálogos linguísticos para a leitura e a escrita. Florianópolis: Insular, 2019. p. 164-200.

SOUZA, Ari J. Estratégias de leitura no curso de Letras: um estudo com os formandos da UNICENTRO. Orientador: Renilson José Menegassi. 2003. Dissertação (Mestrado) - Programa de PósGraduação em Linguística Aplicada. Universidade Estadual de Maringá. Maringá, 2003.

SUCUPIRA, Newton. Parecer nº 977/65. Definição dos Cursos de Pós-Graduação. Brasil, 1965.

TAZAWA, Elaine C. L. Leitura e compreensão de textos acadêmicos: um estudo junto a dois cursos de graduação. Orientadora: Elsa Maria mendes Pessoa Pullin. 2009. Dissertação (Mestrado) - Programa de Mestrado em Educação. Universidade Estadual de Londrina. Londrina, 2009.

UNIVERSIDADE FEDERAL DE SANTA CATARINA. Programa de Pós-Graduação em Linguística. Regimento Interno do Programa de Pós-graduação em Linguística (PPGL) de 24 de fevereiro de 2011. Florianópolis, 2011.

UNIVERSIDADE FEDERAL DE SANTA CATARINA. Programa de Pós-Graduação em Linguística. Resolução $n^{\circ}$ 2/PPGL/UFSC/2018. Florianópolis, 2018. Disponível em:

https://ppglin.posgrad.ufsc.br/files/2011/11/Resolu\%C3\%A7\%C3\%A3o-de-Bolsas-2018-FINAL.pdf. Acesso em: 10 de janeiro de 2018.

ZANELLA, Daniela A. V. A exigência de proficiência em língua estrangeira na pós-graduação em educação. 2003. Dissertação (Mestrado) - Programa de Pós-Graduação em Educação, Universidade de Sorocaba, Sorocaba 2003. 